\title{
Voluntas Symposium: Comments on Salamon and Sokolowski's Re-conceptualization of the Third Sector
}

\author{
Jacques Defourny ${ }^{1} \cdot$ Kirsten Grønbjerg $^{2}$. \\ Lucas Meijs $^{3} \cdot$ Marthe Nyssens $^{4} \cdot$ Naoto Yamauchi $^{5}$
}

(C) The Author(s) 2016. This article is published with open access at Springerlink.com

\begin{abstract}
With their "Beyond Nonprofits: Re-conceptualizing the Third Sector", Salamon and Sokolowski have made an important contribution to the ongoing debate on how to define the third sector. This Voluntas symposium brings together the comments of five leading scholars both supportive and critical of the new definition. The comments are based on a debate held at the conference of the International Society for Third Sector Research, in Stockholm in 2016.
\end{abstract}

Keywords Third sector $\cdot$ Civil society $\cdot$ Social economy $\cdot$ Social enterprise

Kirsten Grønbjerg

kgronbj@indiana.edu

Jacques Defourny

j.defourny@ulg.ac.be

Lucas Meijs

lmeijs@rsm.nl

Marthe Nyssens

marthe.nyssens@uclouvain.be

Naoto Yamauchi

yamauchi@osipp.osaka-u.ac.jp

1 University of Liège, Liègem, Belgium

2 Indiana University Bloomington, Bloomington, USA

3 Erasmus University Rotterdam, Rotterdam, The Netherlands

4 Catholic University of Louvain, Charleroi, Belgium

5 Osaka University, Osaka, Japan 


\title{
How to Bring the Centres of Gravity of the Non-profit Sector and the Social Economy Closer to Each Other?
}

\author{
Jacques Defourny and Marthe Nyssens
}

\section{Introduction}

The attempt made by L.S. Salamon and S.W. Sokolowski (2016) to propose an extended conception of the third sector, beyond typical non-profit institutions, represents a significant progress at various levels. Most importantly, it takes into account some rules and practices that are found in some cooperatives, mutuals and social enterprises. By doing so, the boundaries of the third sector are moved, thus allowing the inclusion not only of non-profit institutions but also of some social economy organizations as conceptualized in many countries, especially across Europe and Latin America.

To emphasize this central advancement and discuss both its strengths and limitations, we will first go back to the very roots of the social economy concept and underline how its centre of gravity differs from the core feature of the non-profit sector. Against such background, it will be easier to discuss the relevance of these extended boundaries.

\section{The Two Facets of the Social Economy Approach}

Defining the social economy generally implies combining two different approaches. The first approach consists in identifying the main legal or institutional forms that are adopted by organizations that do not belong to the private for-profit sector nor to the public sector. For about the last hundred years, three main legal and institutional components of the social economy have been identified: cooperative enterprises, mutuals and associations - although the legal statuses of this latter component vary tremendously from one country to another. In the last two decades, public-benefit foundations have been added as a fourth component.

The second approach to defining the social economy consists in highlighting the common principles of its various components. Stated differently, it consists in showing as precisely as possible why a same umbrella may cover enterprises which are very diverse and how, as a group, they differ from the traditional private forprofit and public sectors. There is no universally accepted definition of the social economy but most expressions of its distinctive features focus on a set of principles: autonomous management, placing service to members or the community ahead of profit (reflected by a limited remuneration of shareholders) and democracy in the ultimate decision-making body (most often the General Assembly).

Comparing this twofold definition with the definition of the non-profit sector as stated in the UN NPI Handbook brings out striking similarities between the two: the organizational criterion echoes that of the legal-institutional approach; implicitly, the private character of NPOs is also found in the legal-institutional approach, since a private legal status is generally adopted by social economy organizations; the 
"self-governance" criterion is very close to the autonomous management in the social economy; the "non-compulsory" criterion that must be met by NPOs is in practice met by all organizations in the social economy.

There are two main differences between the two approaches. (1) The social economy approach emphasizes democratic processes, whereas nothing of the sort is found in the non-profit approach. (2) The non-profit approach, by prohibiting the distribution of profits, excludes practically the entire cooperative component, since cooperatives generally redistribute a part of their surplus to members. It also eliminates part of the mutual component, since some mutual insurance organizations refund surpluses to their members in the form of lower premiums.

Another way of summing up these differences would be to acknowledge that the conceptual centre of gravity of the non-profit approach is the non-distribution constraint, as a signal for a strong public-benefit dimension, whereas the centre of gravity of the social economy owes much to the cooperative tradition, which of course gives clearer space to mutual interest organizations and a central place to democratic control over the organization's goals and functioning.

From this last element, it clearly appears that two issues are at stake when considering ways toward a better convergence of both traditions and even more towards building a "consensus definition" of the third sector. The first issue refers to the ways and the extent to which cooperatives and mutuals (and possibly social enterprises) distribute profits. The second one refers to the way and the extent to which democratic governance has a place in non-profits or not.

\section{Third Sector/Social Economy (TSE) and The Allocation of Profit}

Which Limitations on Profit Distribution are More Relevant? Let us start with the issue of profit distribution and analyse what the attributes of a cooperative's member really are. We argue here that practically all such attributes make a cooperative deeply different from a conventional for-profit shareholding company.

First, one of the best-known features of a cooperative lies in the limitation of the interest/dividend that may be paid on capital shares. Indeed, when a cooperative makes profits, it may only pay an interest that is strictly limited by a cap defined by the law, bylaws or rules that the enterprise must comply with to preserve its cooperative identity. Even in countries not having any law defining a legal status for cooperatives or in countries where the cooperative legal framework is loosely defined, such a cap is imposed by a "registrar" or self-imposed by those enterprises forming the cooperative movement.

In many countries, such a limit is set so as to allow co-operators to receive at best an interest close to what is offered by public bonds. Moreover, this feature is shared by some of the new social enterprise European legal forms, among others the British "community interest company" and the Belgian "social purpose company", which are two emblematic "public purpose" organizations.

This actually makes such payment look much more like an interest rate on a loan than like a dividend-which, by nature, does not have any upper limit, as illustrated by so many strategies, including the most speculative ones, seeking to maximize the total return on investment. Moreover, this limited interest is much less appealing 
than usual bonds because it will only be paid at the end of "good years", and provided the General Assembly decides to allocate some profits to capital remuneration. In many years, it may happen that the cooperative is not able (in case of an overall loss in the operating account) or is not willing (because of other priorities) to pay any remuneration on capital shares.

With such limitations, how could one still consider the purchase of one or some cooperative or social enterprise share(s) as a capitalist investment? Are we not much closer to the simple idea that lent capital deserves at least a moderate remuneration? Only Marx and his disciples argued that capital is per se unproductive and therefore does not deserve any remuneration.

Second, if the cooperative makes substantial profits, the Board and the General Assembly may consider that they partly come from excessive prices paid by member customers. Therefore, these governing bodies may decide that part of profits should be paid back to members as a "rebate" in proportion of the amount of transactions made with the cooperative, not at all in proportion of capital shares. This again underlines the non-capitalist nature of the cooperative's activity.

Collective Reserves Protected by an Asset Lock Most generally, a good deal of profits in a cooperative is kept inside the enterprise and put into reserves as "retained earnings" because the very aim of the cooperative is to develop its activity, not to distribute profits. Moreover the accumulated retained earnings often represent substantial reserves. These are considered differently according to cooperative traditions: in most Latin European countries, these reserves are considered as collective assets inherited from previous generations and they cannot therefore be appropriated by the present generation of members. Consequently, in case members decide or are forced to stop the activity of the cooperative or if they decide to sell their enterprise, the net assets resulting from such operations cannot be appropriated by the members. In other words, collective reserves are protected by an asset lock.

In other countries, like the United States and some other countries of the Anglosphere, the cooperative tradition does not underline the collective nature of inherited reserves in the same way and the law or the bylaws do not necessarily prevent members from an appropriation of accumulated reserves. Such a temptation led some major successful enterprises, especially in the financial industries, towards a process of demutualization, i.e. a conversion of cooperatives into pure capitalist shareholding companies.

In their operational definition of limits on surplus distribution to replace the strict non-distribution constraint for some TSE organizations, Salamon and Sokolowski (2016) require an asset (capital) lock and they limit at less than $50 \%$ the proportion of distributed profit to investors or other stakeholders. Moreover they exclude any type of profit distribution in proportion of capital invested (and therefore potentially all conventional cooperatives)... but this last prohibition does not hold for TSE organizations that have at least $30 \%$ of employees or beneficiaries with special needs. 
This last constraint raises two issues. First, in many cases, such as in work integration social enterprises meeting this "30\% criterion", a proportion of $49 \%$ of profits might be distributed, thus making it quite feasible to offer de facto a higher remuneration to investors than an interest on cooperative shares limited by a cap. A similar situation might result more generally (beyond the case of WISE) from any substantial profit distribution not designed according to capital invested. There is here a clear contradiction that should be dealt with. Second, the criteria of a proportion of at least $30 \%$ of employees or beneficiaries with special needs will prove quite difficult to be operationalized when the social mission of a TSE organization is targeted towards the community at large (for example in the environmental field).

To reflect the "public purpose" of TSE organizations by better combining key features from both the non-profit and the social economy approaches, we would therefore suggest to keep the authors' first three criteria and to transform the fourth one so as to avoid the above contradiction and to have four compulsory criteria that are easily observable characteristics: (i) Pursuing a legally binding social mission; (ii) Operating under a "asset lock"; (iii) Being prohibited from distributing more than $50 \%$ of profits; and (iv) Limiting by a clearly defined cap the interest that may be paid on capital shares.

Which Relation to Democratic Governance? In many academic circles involved in non-profit studies, mentioning democratic principles or even a participatory governance looks strange and does not seem related to the core nature of the third sector. In some regions or fields indeed, the non-profit sector is dominated by foundations which are managed by trustees.

In many other regions, foundations do not represent the main component of the non-profit sector; sometimes, they even correspond only to a very small part of the social economy. Then it is worth looking at other governance structures, like those of cooperatives, mutuals and associations. Let us take first cooperatives, which, as we saw, are not capitalist but must have another fundamental goal that is appealing enough to its members: it is the "mutual interest" of these members, pursued by launching, owning and managing an enterprise that provides them with goods or services of a better quality, at a better price or more generally under better conditions than what is offered by other firms or by the state. In other terms, the very nature and purpose of the cooperative lies in what is named the twofold identity ("double qualité" in French) of members: they are at the same time coowners (associates) and workers/users/customers/providers of their cooperative and therefore, governance mechanisms must be adapted to this twofold stance. Far from just being an ideological preference, the "one person, one vote" rule in the General Assembly, i.e. the ultimate controlling body, has been and is still successfully implemented by cooperatives in all world regions and in many industries. Although demanding (as democratic life), it appears on the overall as a device that keeps in line the interests of members as enterprise co-owners and as enterprise's customers/ users. 
Democracy in the decision-making process is also a key feature in all associations, where statutes impose the rule of "one person, one vote" in the ultimate controlling body. Most legal frameworks designed for European social enterprises also require this rule or at least a strict limit on the number of votes per member.

Such audacious rule expresses an economic quest for (a form of) democracy at the heart of market economies, not just in the non-market fields of activity. Then, how to avoid seeing clearly a kinship, not just a historical common matrix, between cooperatives and associations? The typical cooperative and the typical association may be seen as twins, both "channelling" democratic rules and practices, respectively, in market activities and (mostly) in non-market activities. These objectively observable and operational characteristics are part of the core of the social economy identity. To this extent, it is a bit strange that the issue of democratic governance appears as a blind spot and is not discussed in this proposal towards a consensus conceptualization.

\section{Conclusion}

There would be a lot more to say about several key-related issues that go beyond this note. First and foremost, it would be quite relevant to revisit the "rationale of the third sector" through which Gui (1991) theorizes the latter as pulling together all private organizations whose beneficiary category (i.e. to which the net surplus is allocated) is composed of stakeholders other than investors. The third sector then gathers "mutual benefit organizations" (in which the stakeholder dominant category that has the ultimate power is also the beneficiary category), and "public benefit organizations" (in which the beneficiary category is different from the dominant category).

Such theorization might offer strong grounds to assemble broad sets of organizations that are clearly different but nevertheless share enough common features to form the third sector of modern economies. In our view, the "public purpose" dimension, combined with relaxing the non-profit distribution constraint, represents an original and interesting avenue to enlarge the third sector conceptualization strictly based on non-profit institutions. It calls, however, for further research efforts to better understand the great diversity within the cooperative landscape and in the fast developing landscape of social enterprises.

As to social enterprises, as many of them actually adopt a cooperative or nonprofit legal form, they should not appear as an additional component of the third sector that seems quite distinct from non-profits and cooperatives, as Fig. 1 may suggest. Moreover, as we do argue elsewhere, all three classical "sectors" of modern economies may serve as matrices from which social enterprise models can emerge (Defourny and Nyssens 2016): a "non-profit entrepreneurial" model and a "social cooperative" model naturally stem from the third sector/social economy; a "social business" model may appear through quite advanced CSR strategies in the private sector when the social mission is not just instrumental to profit maximization; finally, it is increasingly possible to identify a public-sector social enterprise model, shaped and controlled by quite specific public policies. 
Overall, the present quest for a "consensus definition" of the third sector might be seen as paving the way to a complementary approach: after the present exercise, that tries to extend the boundaries of the third sector while keeping the non-profit sector as the centre of gravity, it could be fruitful to try moving both centres of gravity (of the non-profit sector and of the social economy) towards each other in a more balanced way, so as to explore common defining features related to both profit distribution and governance.

\section{Commentary on "Beyond Nonprofits: Re-conceptualizing the Third Sector"}

\section{Kirsten Grønbjerg}

The Third/Social Economy (TSE) model proposed by Salamon and Sokolowski builds on major advances in scholarly work on non-profits, volunteering and related concepts and seeks to build the foundation for new advances. The paper makes a cogent argument for expanding the definition of the sector beyond the traditional "Core" definition and it helps us understand cross-sector relations between the TSE and the for-profit worlds. However, it is almost silent on the TSE-government relationships and does little to help us think about national contexts or policy debates. Its major (and very significant contribution) lies in drawing out attention to what happens at the boundaries of the core.

I greatly appreciate the opportunity to comment on the efforts by Lester Salamon and Wojciech Sokolowski, and their collaborators to define the "Third/Social Economy" sector (TSE). This is clearly an ambitious project and we are well served by the groundwork the team has undertaken.

It also comes at an opportune time. We have made great advances in scholarly work on nonprofits and closely related concepts. This is evidenced by the growing number of scholarly associations and especially journals devoted to the field along with an explosion of doctoral dissertations (now totalling more than 12,700) ${ }^{1}$ and articles in peer-reviewed journals (in excess of 120,000 since 1980). Clearly, no single researcher or even team of scholars can master the field or its complexities.

The growth in research has been greatly facilitated by the development of systematic longitudinal data. In the U.S., the examples include data on charitable contributions (Giving USA), financial information reported by tax-exempt entities on Form 990 (available through the National Center for Charitable Statistics at the Urban Institute), surveys on volunteering (Current Population Survey) and time-use (Bureau of Labor Statistics), and quarterly covered employment and wages for non-profit paid employment (Johns Hopkins Center for Civil Society Studies, Indiana Nonprofit Sector project ${ }^{2}$ ). There have also been significant advancements

\footnotetext{
${ }^{1}$ Estimates updated from Grønbjerg (2015) using ProQuest to search dissertations with the following terms in the title or abstract: ((philanthrop*) OR (charit*) OR (non-profit*) OR ("third sector") OR ("voluntary sector") OR ("civil society") OR ("not-for-profit")). The counts would more than double if "volunteer*" was also included among the search terms.

${ }^{2}$ See http://ccss.jhu.edu/research-projects/nonprofit-economic-data/ and http://www.indiana.edu/ $\sim$ nonprof/results/inemploy/index.php.
} 
in the development of survey instruments on nonprofit and TSE-related topics and on sampling designs targeted both at surveying organizations and individuals.

The key challenge here continues to be how to build these empirical efforts into (national) systems of accounts and other routine data collection efforts. This is a technical, a political and a conceptual challenge. It is technical in the sense that much data are of questionable quality, designed for administrative purposes only and stored in formats that are not easily linked to other data. It is political in the sense that the producers and owners of the data are not easily convinced that refinements or additions are needed or cost-effective. It is a conceptual challenge because it requires careful efforts to define the unit of analysis-individuals, groups/collectivities, organizations (not always easily distinguished from groups) and networks.

But it is certainly also a conceptual challenge to define the boundaries of the "sector"-hence the Salamon and Sokolowski effort and proposed model for defining the "Third/Social Economy" sector. As outlined in Salamon and Sokolowski (2016), there are two dimensions to the basic TSE model: the unit of analysis (institutions/organizations vs. individuals) and scope (core vs. periphery).

Turning first to the focus on institutions, the "easy" part here is to define the "core" - what most of us in the field think of as the "traditional" nonprofit institutions: organizations that are private (unlike government), self-governing (unlike government) and non-compulsive (unlike families?), ${ }^{3}$ and do not distribute profits (unlike businesses). I would add substantive goals (e.g. mission) or publicbenefit purpose (as preferred by Salamon and Sokolowski). ${ }^{4}$

The more challenging - and interesting — part of the model comes when we begin to look more closely at what happens at the boundaries of the Core. The devil is in the details. Take the question of profit distribution and how that applies to establishing a boundary between the Core and the for-profit sector. If we allow for ANY profit motives to operate, how much profit can be redistributed? Does it matter whether profit distribution is formally permitted but only partially implemented (e.g. guided by norms that are consistently more restrictive than the bylaws)? Does it matter who makes the decision about distribution of profit (managers, association members or investors) or how decision-making takes place? Or who are the recipients of the profits (corporate investor(s), individual investor(s), a membership or mutual benefit association or philanthropic institutions)? Does it matter how the profit is obtained (e.g. using disabled/disadvantaged workers, green technology or equitable pay)?

\footnotetext{
${ }^{3}$ I am not convinced that membership in the family is as compulsory as Salamon and Sokolowski claim, or that it is the best contrast to the free choice that defines the non-profit Core. Yes, a particular woman gives birth to you and that cannot be changed (at least not with our current technology), but the family as an institution varies enormously across societies and social groups. In some societies, the family is indeed a total institution, all-encompassing and compelling. In others, family units form and dissolve frequently and individual members come and go.

4 I am troubled by the argument that "reasonable" compensation of directors or employees is sufficient or appropriate for identifying organizations with a "public benefit" purpose. The boundary between reasonable and excessive compensation is murky and very slippery, but needs attention if it is to serve as a criteria for defining this important concept. What is "reasonable" for a corporate CEO of a Fortune 500 Company is beyond the wildest imaginations of those working at or below minimum wages.
} 
The TSE model does a nice job laying out many of these boundary issues between the nonprofit Core and business corporations. But I suspect the really interesting questions come when you begin to look very closely at the boundary definitions and where the tipping points should be. For examples, which of the profit distribution dimensions outlined above (and which tipping points) are close enough to the Core to belong in expanded definition of TSE (the periphery), and which belong clearly in the for-profit sector? And should we worry about how organizational behaviour about profit distribution changes over time? (For a discussion of these and related topics, see Child 2015, 2016.) As my examples in the previous paragraphs suggest, I do not find the operational definitions as laid out in the TSE model entirely convincing. For example, are cooperatives and mutual benefit firms really so fundamentally different from social ventures and enterprises that they belong on opposite sides of the "core" in Fig. 1? If so, why?

The model is surprisingly less developed when it comes to the boundaries between the core non-profit and the public sectors. Are there not similar questions about defining the underlying dimensions (and the tipping points) for "privateness" and "self-governance" as there are about profit distribution? It is telling that Fig. 1 shows very little/no overlap between government and the nonprofit "core" suggesting that this distinction is clear-cut and/or not relevant for a conceptual model. I am not convinced that either assumption is valid.

Turning now to the question of applying the TSE model to individuals, I find the framework to be very useful also here and agree with the defining characteristics, e.g. benefitting others (not family) and not casual, paid or compulsory. However, there are some important blurred boundaries here also. For example, how do we define "casual" volunteering and where does "spontaneous" volunteering fit (e.g. helping someone or a community in an emergency vs. helping someone cross the street). How and where should we draw the limits of the family and kin? What constitutes compulsory? And should we distinguish informal volunteering from social exchanges of favours and benefits? It is also not clear to me why volunteer work for government would not qualify as part of the Third/Social Economy sector. After all, governmental units are also likely to be public-benefit organizations and the distinction is not likely to be meaningful to the individuals involved.

The model raises several questions for me beyond how far beyond the Core should/can we go. First, does it help us understand cross-sector relations and dynamics? My answer is yes, to some extent, but we need a finer grained analysis that recognizes how these relationships vary across field of activity (whether defined in terms of economic activity or primary purpose).

For an example, Grønbjerg and Smith (2015) have outlined how cross-sector relations vary across major nonprofit fields (using health, education, human services, arts and culture, and religion as our examples) along six major dimensions: (1) the overall economic size of the field-reflecting political salience; (2) the nonprofit share of the economy (aligns with Salamon's regime model); (3) the functional division of labour-who does what; (4) the political economy - state policy tools and application to nonprofits; (5) marketization-nonprofits and the market economy; and (6) nonprofits and the informal sector-opportunities for 
volunteering and donating, for civic engagement and advocacy, and for building social capital more generally.

The TSE model picks up well on the marketization dimension (5) and on the volunteering aspects of the informal dimension (6). It would help also on dimensions (2) and (3). But as noted earlier, it is almost entirely silent on our fourth dimension: how nonprofits (or in this case, the TSE sector) relates to government. That dimension needs careful attention to the policy tools government employs, e.g. direct service provision, producer subsidies (in the form of grants/contracts, financing and tax exemptions), consumer subsidies (in the form of vouchers, subsidized fees, tax credits and deductions), and regulations. Notably, these policy tools vary enormously across fields of activities; they also vary across national boundaries.

So, yes, the TSE model does help us understand, at least to some extent, crosssector relations. However, we need to pay attention to fields of activities and we need much more nuanced attention to government/TSE interactions. I am also not sure how well the TSE model helps us in thinking about national contexts and policy debates. At the very least, we need careful consideration of the various modules and why some may be especially prominent and others invisible/non-existing in a particular national context, or we may miss important nuances.

But these comments are not meant as a criticism-quite the contrary. I find the TSE model stimulating and particularly useful in helping us understand what happens at the boundaries of the Core. The mapping exercise by itself is extremely useful and a major contribution. It directs attention to what may be among the most interesting and revealing dynamics, especially at the boundary between the Core and the for-profit sector.

\section{Commentary on Re-conceptualizing the Third Sector from Japanese Viewpoints}

\section{Naoto Yamauchi}

The purpose of this comment is to evaluate the re-conceptualization process discussed in Salamon and Sokolowski (2016) in the light of recent developments that the Japanese third sector has undergone in the past couple of decades.

\section{Operational Definition for the Third Sector}

According to the UN Statistics Division (2003), in order to be in-scope of a suggested NPI satellite account, non-profit institutions (NPIs) must have five features: namely, they must be organizations, self-governing, private, non-compulsory and non-profit distributing. Salamon and Sokolowski (2016) proposes an alternative definition for the 'extended' third sector by loosening the definition by replacing 'non-profit distributing' with 'totally or significantly limited from distributing any surplus they earn to investors, members, or other stakeholders,' while keeping the other four features virtually unchanged. While this amendment 
was initially designated mainly for the development of the third sector or social economy in Europe, it is quite reasonable and realistic taking into account the recent change of the third sector in Japan.

Salamon and Sokolowski (2016) also proposes five conditions (the first three of which are mandatory) that organizations in the extended third sector must fulfil to meet the "significant limit on surplus distribution" requirement. Those are

(1) They must have an explicit and legally binding social mission

(2) They must be prohibited from distributing any more than $50 \%$ of any profit to outside stakeholders

(3) They must operate under a capital lock that requires that all retained surplus must be used to support the organization or to support other entities with similar social purposes.

(4) They must include at least $30 \%$ of individuals with specified special needs among their employees and/or beneficiaries.

(5) They must be prohibited from distributing any profit they may earn in proportion to capital invested or fees paid.

While those conditions are somewhat comprehensive and concrete, and similar to the criteria used to sort out social enterprises in Japan (see next section), some of them are debatable, and some may not be statistically operational. For instance, it may be difficult to get enough information on the percentage of individuals with special needs.

Salamon and Sokolowski (2016) also suggests that not only organizations but also informal and individual components are important elements of the extended third sector. They are quite right in the sense that individual activities are important elements to shape the extended third sector. It is worth noting, however, that individual activities through organizations are already counted even in the conventional definition of the third sector, and thus the net addition to the extended third sector is individual activities done directly, as Salamon and Sokolowski (2016) notes. Since individual activities should be counted in the household sector in the SNA convention, it may be a little misleading to add informal and individual activities on the extended third sector.

\section{Recent Developments in the Japanese Third Sector}

There has been a fundamental legal reform of non-profit corporate status in the Japanese third sector. The number of new types of corporations, namely, general incorporated associations and foundations, has increased since the new corporation system started (Okuyama and Yamauchi 2015). While they are legally not-for-profit and clearly within the NPI sector, their behaviour is close to for-profits to some degree. For instance, they do not have to operate under a capital lock, and retained surplus may be distributed to stakeholders.

Social enterprises, as typical hybrid organizations, are receiving people's attention, and their activities have been expanding rapidly. The Cabinet Office of Japan recently estimated the aggregate size of social enterprises (Cabinet Office 
2015). According to the report, the social enterprise must meet the following conditions.

(1) The enterprise should have mainly social or environmental aims.

(2) It should agree that it is a business with primarily social or environmental objectives, not with the pursuit of profit.

(3) It should agree that it is a business whose surpluses are principally reinvested for that purpose in the business or community rather than mainly being paid to shareholders and owners.

(4) It should not pay more than 50 percent of profit or surplus to owners or shareholders.

(5) It should not generate less than 50 percent of income from business.

According to the results, 11.7 percent of all Japanese small and medium enterprises are assumed to be social enterprises. The percentage of paid employees for social enterprises is 13.2 percent. Contributions to GDP in terms of value added produced by social enterprises are over 3 percent.

There are no special legal categories for social enterprises in Japan. 91 percent (18.7 million entities) of total social enterprises (20.5 million) are for-profit small and medium enterprises, while 9 percent (1.8 million) are non-profits (incorporated associations and foundations and specified non-profit corporations). Therefore, the treatment of social enterprises operating as for-profit legal forms is crucial. If social enterprises operating as for-profit legal forms were excluded from the extended third sector, we would substantially underestimate the real size of the extended third sector.

Generally speaking, an organization operates multiple activities or business units. In Japan, only 17 percent of the total revenue of social enterprises is generated from social business, while 83 percent is from non-social business (Cabinet Office 2015). In the case of hybrid organizations like social enterprises, should we include an organization as a whole or only a social business unit in the extended third sector? The choice of analytical unit has become important, since organizational hybridity could widen the differences between the organization and the activity.

\section{Some Practical Implications}

Based on the discussions so far, we would like to extend some practical suggestions. First, there could be more than one definition of the third sector, from the narrowest to the broadest, depending on the divisions included. It is, in fact, difficult to choose one right definition. Now we would like to propose multiple definitions of the third sector, analogical to the definitions of money, namely, M1, M2, M3, etc. For example, TS0 would be the narrowest common core of the third sector. TS1 would be the common core plus value of volunteering. TS2 could be defined as TS1 plus cooperatives and mutuals operating under certain limitations on surplus distribution. TS3 could be TS 2 plus social enterprises operating under conditions specified in the previous section. If data on each definition are available, users can choose freely suitable concepts and statistical data depending on their aims. It is also possible to 
make international comparisons on TS1, TS2 and TS3 respectively, as long as comparative data are available.

Second, in general one organization often runs more than one activity, both forprofit and not-for-profit activities. Hence, it is necessary and useful to identify organizations and activities as analytical units. It is particularly important in the case of hybrid organizations like social enterprises.

Third, informal and individual components should be more elaborated, if they are to be included in the extended third sector. For instance, paid volunteering is very common in the Japanese nursing care sector. They are often paid for example 50 percent of the market wage rate, and it is not clear whether this type of job can be treated as volunteering, or should be treated as paid work subject to personal income tax and/or labour regulations. Semi-compulsory volunteering is also widespread at school and local community in Japan. For example, parents feel it extremely difficult to refuse volunteering at school. There must be huge diversity in the form of volunteering, not only in developed countries, but also in the developing world. The new concept of the extended third sector should fully take into account this sort of diversity.

\section{Commentary on "Beyond Nonprofits: Re-conceptualizing the Third Sector"}

\section{Lucas Meijs}

\section{Introduction}

The aim of this commentary is to explore whether the re-conceptualisation of the third sector also has added value in countries like The Netherlands that have a large civil society or third sector (Salamon et al. 2004; Civicus/De Nieuwe Dialoog 2006). Following that exercise, four questions will be raised on the re-conceptualization. A first issue addresses the question of organizational diversity. A second issue is that the point of reference for the re-conceptualization still is government, neglecting the business perspective. This is followed by a short comment on the capital lock in social enterprises and a final remark about the changing definitions of volunteering.

As a traditional 'frontrunner' third sector country, the Netherlands has more to lose than to gain from any re-conceptualization. However, having a long history of particulier initiatief (private initiatives), maatschappelijk middenveld (societal midfield), pillarization, pacification and state funding (see Hupe and Meijs 2000; Habraken et al. 2013) potentially means that old persisting frames dominate the public discourse. As a consequence, in some policy areas, the old arrangements are not recognized as independent third sector anymore, new solutions get much attention and maybe the re-conceptualization will help to solve this myopia. 


\section{The Added Value of the Re-conceptualization}

The main added value of the re-conceptualization in the Netherlands is indeed that it broadens the third sector into combining the old subsidized organizations that are confused with government and the new emerging initiatives and social enterprises that are easily confused with business. Indeed, it is important that the reconceptualization has the institutionalized structural non-profit definition as the core emphasizing for Dutch policy makers and researchers that the institutionalized, paid-staff-dominated, subsidized non-profit organizations are still part of the third sector. Nevertheless, explicitly incorporating mutuals and cooperatives, the traditional volunteer-dominated mutual support and benefit membership associations in leisure and sports is important as in many cases this part of the third sector is ignored in the governmental debates on health care and social services. Third, the re-conceptualization will be a jump starter for the debate in the Netherlands on the percentage of profit distribution allowed not only in social enterprises, but also, for example, in the new cooperatives in energy production and care provision. The last important point is that the re-conceptualization also emphasizes volunteering as a building block of the third sector in itself, instead of only being a resource.

\section{Some Questions on the Re-conceptualization}

A first question is whether the new conceptualization will be able to join the different words that academic researchers use. For example, in the business school community, scholars focussing on international business strategy and corporate social responsibility seem to favour the term non-governmental organization, while scholars focussing on management, organizational behaviour and internal organization favour the term non-profit organizations and social enterprise. Following the re-conceptualization, the suggestion would be to use the term TSE sector organizations for all, making it all the more important to abide by the reconceptualization's emphasis on acknowledging that there are still differences between organizations that are aimed at clients (service civil society), members (mutual civil society) or policy (campaigning and advocacy civil society) (see Meijs 2012).

A second question can be raised about the seeming dominance of using the governmental sector in defining the third sector. This dominant cynosure point might hinder the embrace of the third sector concept by social entrepreneurs, who define themselves in terms to of businesses or in contrast to non-profits using business-like behaviour and rhetoric (Dart 2004). However, even more pressing is that the re-conceptualization ignores the existence of the BONGO in which a business or the business sector controls the NGO (see van Tulder and van der Zwart 2006). Beyond this, definitional issues are created for cross-sector partnerships between the business sector and the TSE sector. If these take the form of social enterprises, these are incorporated. Nonetheless, what about organizations such as the Roundtable for Sustainable Palm Oil, ${ }^{5}$ for instance, a global multi-stakeholder

\footnotetext{
5 http://www.rspo.org/.
} 
organization focused on sustainable palm oil. Other borderline organizations are the shareholder foundations that control companies (see Seghers et al. 2015) and the corporate foundations that carry out part of the firm's CSR policies (see Roza, forthcoming). These are technically part of the third sector but probably need to be checked on their self-governing feature or the so called distance to the company (see Maas and Meijs, forthcoming).

A third question can be raised about the inclusion of a capital lock on retained earnings for in-scope institutions. Although there are good reasons to keep the capital lock at $100 \%$ of retained earnings, one could also imagine that new financial instruments, such as social impact investing or other innovations, might lead to relaxing the capital lock to something below 100 percent.

The last question addressed in this commentary relates to volunteering. An important development in volunteering is the growing importance of the third party model in which an organization, such as an educational institute in service learning or a company in corporate volunteering, sends its members, students or employees to a third sector organization to volunteer (see Haski-Leventhal et al. 2010). This trend poses two issues. First of all, it will not be easy to asses if these activities indeed are non-compulsory and have a meaningful element of choice. Second, there is also a risk of double counting these volunteers, with both the sending organization, and the receiving organization claiming them.

\section{Conclusion}

The major added value of the re-conceptualization is the explicit broadening of the third sector creating an insightful new figure. The probably next development is to focus on the interface with the business sector.

Open Access This article is distributed under the terms of the Creative Commons Attribution 4.0 International License (http://creativecommons.org/licenses/by/4.0/), which permits unrestricted use, distribution, and reproduction in any medium, provided you give appropriate credit to the original author(s) and the source, provide a link to the Creative Commons license, and indicate if changes were made.

\section{References}

Cabinet Office (2015). Report on the Aggregated Activity Size of Social Enterprises in Japan. Cabinet Office NPO Homepage.

Child, C. (2015). Mainstreaming and its discontents: Fair trade, socially responsive investing, and industry trajectories. Journal of Business Ethics, 130(3), 601-618.

Child, C. (2016). Tip of the Iceberg: The nonprofit underpinnings of for-profit social enterprise. Nonprofit and Voluntary Sector Quarterly, 45(2), 217-237.

CIVICUS/De Nieuwe Dialoog. (2006). CIVICUS civil society index report for the Netherlands. Amsterdam: De Nieuwe Dialoog/CIVICUS.

Dart, R. (2004). Being "Business-like" in a nonprofit organization: A grounded and Inductive Typology. Nonprofit and Voluntary Sector Quarterly, 33(2), 290-310.

Defourny, J., \& Nyssens, M. (2016). Fundamentals for an International Typology of Social Enterprise Models, ICSEM Working Papers No. 33, The International Comparative Social Enterprise Models (ICSEM) Project, Liege. 
Grønbjerg, K. A., \& Smith, St. R. (2015). the changing dynamics of government-nonprofit relations: Advancing the field-A review essay. Revised version of paper presented at Annual conferences of the International Society for Third-Sector Research (2014); the American Political Science Association (2014); and Association for Research on Nonprofit and Voluntary Action (2013). Online at https://www.researchgate.net/publication/301291814_The_Changing_Dynamics_of_GovernmentNonprofit_Relations_Advancing_the_Field_-_A_Review_Essay.

Gui, B. (1991). The economic rationale for the third sector. Annals of Public and Cooperative Economics, 62(4), 551-572.

Habraken, R., Meijs, L. C. P. M., Schulpen, L., \& Temmink, C. (2013). Dutch civil society at crossroads. Development in Practice, 23(5-06), 742-754.

Haski-Leventhal, D., Meijs, L. C. P. M., \& Hustinx, L. (2010). The third party model: enhancing volunteering through governments, corporations and educational institutes. Journal of Social Policy, 39(1), 139-158. doi:10.1017/S004727940990377.

Hupe, P., \& Meijs, L. (2000). Hybrid governance, the impact of the nonprofit sector in the Netherlands. Rotterdam: Erasmus University Rotterdam.

Maas, S., \& Meijs, L. C. P. M. (forthcoming). Glocal Corporate Philanthropy: A Cross-national Analysis of the Inter-relation between McDonalds and the Ronald McDonald House Charities. Paper to be presented at the Academy of Management Conference, August 5-9, 2016, Anaheim, California, US.

Meijs, L. C. P. M. (2012). Reinventar la sociedad civil: A la tercera va la vencida! [Reinventing civil society: three is the charm]. In V. Perez-Diaz (Ed.), Europe ante una crisis global Economia, geoestrategia, sociedadcivil y valores. Madrid: Gota a Gota.

Okuyama, N., \& Yamauchi, N. (2015). Giving in Japan: The role of philanthropy in strengthening civil society. In P. Wiepking \& H. Femida (Eds.), The Palgrave handbook of global philanthropy. New York: Palgrave Macmillan.

Roza, L. (forthcoming). Employee engagement in CSR. A collection of essays, Rotterdam School of Management. PhD Dissertation, Rotterdam.

Salamon, L. M., \& Sokolowski, W. (2016). Beyond nonprofits: Re conceptualizing the third sector. Voluntas. doi:10.1007/s11266-016-9726-z.

Salamon, L. M., Sokolowski, W., \& Associates. (2004). Global civil society: Dimensions of the nonprofit sector (Vol. 2). Bloomfield, CT: Kumarian Press.

Seghers, V., Delsol, X., Gautier, A., Bothello, J., \& Le Brun, F. (2015). Shareholder foundations: The First European study. Paris: Prophil.

UN Statistics Division. (2003). Handbook on nonprofit institutions in the system of national accounts. New York: UN Statistics Division.

van Tulder, R., \& van der Zwart, A. (2006). International business-society management; linking corporate responsibility and globalization. London: Routledge. 